\title{
1 Revealing rangeomorph species characters using spatial analyses
}

2 Emily G. Mitchell ${ }^{1}$, Charlotte G. Kenchington ${ }^{2}$, Simon Harris ${ }^{3}$ and Philip R. Wilby ${ }^{3}$

3

4

${ }^{1}$ Department of Earth Sciences, University of Cambridge, Downing Street, Cambridge CB2

$53 E Q, U K$.

6

$7 \quad{ }^{2}$ Department of Earth Sciences, Memorial University of Newfoundland, St. John's, NL A1B $3 X 5$

$8 \quad$ Canada.

9

${ }^{3}$ British Geological Survey, Nicker Hill, Keyworth, Nottingham NG12 5GG, United Kingdom. 11

*Corresponding author email address: ek338@cam.ac.uk.

13

14 
15 Abstract: Rangeomorphs dominate the Ediacaran Avalonian macrofossil assemblages of

16 Charnwood Forest, UK ( 562Ma). However, their unfamiliar fractal architecture makes

17 distinguishing phylogenetically reliable characters from intraspecific features difficult.

18 Fortunately, spatial analysis of large in-situ populations offers an independent means of

19 assessing their taxonomy. Populations of a single biological species are likely to exhibit similar spatial distributions due to their shared responses to the biological and ecological processes

21 acting upon them. As such, spatial analyses can be used to interrogate which are the most taxonomically deductive characters in similar species. We used Random Labelling Analyses to investigate the presence/absence of characters of Primocandelabrum boyntoni, $P$. aethelfalaedia and P. aelfwynnia on the North Quarry 'B' surface. The resultant spatial distributions were compared to observed characters using goodness-of-fit tests to determine which characters were associated with unique populations, and which were found across multiple populations. We found that $P$. boyntoni and $P$. aelfwynnia had statistically indistinguishable character distributions, suggesting that they represent a single biological species, and that they exhibited significantly different distributions to $P$. aethelfalaedia, suggesting that there are two (rather than three) Primocandelabrum species present on the B surface. Furthermore, we found that the distribution of Concealed versus Unconcealed 1st order branches across all specimens exhibited significantly different, density-dependant behaviour, with Unconcealed branching occurring in areas of higher density populations, and Concealed branching occurring in the lower

Primocandelabrum density areas. We speculate that unconcealed branches may have been a response to the reduced availability of resources in higher density areas, implying rangeomorphs were capable of ecophenotypic responses.

Key words: Ediacaran, Rangeomorph, Spatial analyses 


\section{Introduction}

41 The Avalonian Assemblage of Ediacaran organisms contains some of the oldest known examples of macroscopic organisms in the fossil record, and is known primarily from south east Newfoundland (Clapham et al. 2003, Hoffmann et al. 2008, Narbonne et al. 2009) and Charnwood Forest, UK (Wilby et al. 2011, Kenchington et al. 2018). Avalonian macrofossils share few similarities with living taxa, making organism biology, phylogenetic relationships and ecological interactions difficult to assess (Liu et al. 2015, Erwin et al 2011, Xiao \& Laflamme 2009 ). Their communities are dominated by rangeomorphs, a proposed clade of "fractallybranching" organisms (Narbonne 2004, Hoyal Cuthill and Conway Morris 2014, Erwin et al. 2011). However, their unfamiliar fractal architecture makes distinguishing phylogenetically reliable characters from intraspecific features difficult (Liu et al 2015b, Kenchington and Wilby

One of the largest and most diverse Avalonian communities is preserved on the so-called Bed 'B' bedding-plane surface in Charnwood Forest (UK) which, at $115 \mathrm{~m}^{2}$ surface area and with at least 18 different taxa, is comparable to that on the Mistaken Point 'E' surface in Newfoundland (Wilby et al. 2011). The multifoliate, stemmed rangeomorph Primocandelabrum (Hofmann et al. 2008) comprises a significant proportion of the Bed 'B' community, and is principally diagnosed by its coarse branching, the triangular outline of its crown, and by having typically rotated, unfurled folia (first order branches) that are proximally inflated, and second order branches that are typically displayed, unfurled and medially inflated (Figs. 1 and 2; Hofmann et al. 2008, Kenchington and Wilby, 2017). Prior statistical analyses by Kenchington and Wilby (2017) used multivariate cluster analyses to formally describe three Primocandelabrum species using both continuous (e.g. length to width ratios) and discreet (e.g. rotated first order branches, Fig. 2) characters, and revealed a hitherto unrecognized morphological variability in Primocandelabrum. Within the Kenchington and Wilby results there is overlapping variation between the individuals in the clusters (Fig. 3), with individuals in different clusters sharing some of the same characters and some characters not being $100 \%$ unique to a cluster. Their analyses suggested two or three Primocandelabrum species: $P$. boyntoni, $P$. aelfwynnia and $P$. aethelflaedia. As such, there remains uncertainty regarding the number of species present on Bed 'B'. 
notable examples of thousands of these organisms preserved in-situ on successive bedding planes (Wood et al. 2003, Kenchington and Wilby 2014, Liu et al., 2015). Their sessile habit and their preservation in life position means that their position on a bedding plane encapsulates their lifehistory: that is, their position is a combined record of the abiological, biological and ecological processes that impacted them during their life. Consequently, spatial analyses can be used to investigate otherwise cryptic aspects of Ediacaran life, such as how they reproduced (Mitchell et al. 2015) or how they interacted with each other (Mitchell and Kenchington 2018) and/or their environment (Mitchell and Butterfield 2018) and provide a complimentary record to prior ecological analyses of population size-frequency distributions (Darroch et al. 2013, Wilby et al 2015). sessile organisms: 1) dispersal processes, 2) associations with local habitat heterogeneities, 3) direct inter-specific interactions, and 4) density-dependent effects (Wiegand et al. 2007). The first three represent inter-specific interactions and these can have either a negative impact on populations, such as competition for limited resources, or a positive impact, such as facilitation, whereby one species enhances the survival of another. Density-dependent effects include, for example, Janzen-Connell effects, whereby a specialist consumer, such as a pathogen or a taxonspecific herbivore, leads to density-dependent deaths (Velázquez et al. 2016). In non-motile systems, such as the Avalonian ones, density-dependent effects are limited to pathogens because macroscopic predators/herbivores are absent (e.g. Liu et al. 2015). Pathogens transfer between organisms in high-density areas more easily than between those in low density areas, thus creating differential mortality patterns based on relative density (Wiegand et al. 2007a). Significant density-dependent mortality can be detected via the spatial distributions of taphomorphs, such as ivesheadiomorphs, and/or by the incorporation of effaced characteristics into analyses (cf. Mitchell and Butterfield 2018). Consequently, well preserved specimens, such as those considered in the present study, can be assumed to not have been significantly impacted by pathogenic mortality effects and, hence, only the first three processes need be considered. Each of the three inter-specific processes have numerous factors which impact the resultant spatial distributions. The spatial distributions induced by dispersal processes are determined by the following factors: the type of dispersal process (e.g. propagule or 
stolonifereous), the number of offspring, the height at which propagules are released, the current speed (which is assumed conserved across a given community at a given time), and the relative density of the settled offspring (e.g. Yamamichi et al. 2014). Habitat influences can vary within any one habitat by operating at different spatial scales, having a positive or negative impact and/or vayring in their relative strength (Wiegand et al. 2007b), as can interspecific interactions (Lingua et al. 2008). Acting in combination, these factors produce an enormous number of possible different combinations of spatial distributions: just taking each factor as discrete (which would be a very simplified model, since only $2 / 11$ of the characters are discreet) would give almost 40 million different possible combinations. Consequently, if two populations exhibit the same spatial distribution, it is reasonable to infer that the same abiological, biological and ecological processes have impacted both populations. This situation is most likely to happen when the two populations are, in fact, just a single species.

Spatial analyses have previously been used within the Avalon Assemblage to investigate the possible taxonomic affiliations of enigmatic forms referred to as ivesheadiomorphs and Lobate Discs (Mitchell and Butterfield 2018). These have variously been suggested to be either the decayed remains of other taxa (i.e. taphomorphs, Liu et al. 2011), microbial colonies that were independent of macro-organisms or their carcasses (cf. Laflamme et al. 2011), sediment load structures (Wilby et al. 2011), or a combination of these (Kenchington et al 2018).

Comparison of the spatial distributions of the populations of ivesheadiomorphs and Lobate Discs on the E surface of Mistaken Point revealed that the ivesheadiomorphs were most likely the taphomorphs of Fractofusus and Charniodiscus, while Lobate Discs were found to most likely not be the taphomorphs of any of the other taxa on the surface (Mitchell and Butterfield 2018).

In this study, we extend the use of spatial analyses to interrogate what constitute the most taxonomically informative characters in a single rangeomorph genus. We test the impact of morphological characters on taxonomic differences by assuming that if two named 'species' differ by a single morphological character but exhibit the same spatial distributions then that character is unlikely to be taxonomically significant and more likely represents a differential response to some stimulus. We use spatial analyses to test current taxonomic definitions for multifoliate taxa on Bed 'B', contrasting each of the three proposed species of Primocandelabrum with another abundant multi-foliate rangeomorph (the "dumbbell" of Wilby 

and rotation (Fig. 2), exhibit density-dependant behaviour.

\section{Data}

135 Characters were assigned to Primocandelabrum and dumbbell specimens using the data from Kenchington and Wilby 2017. Fourteen discrete (i.e. categorical) Primocandelabrum characters are recognised, of which 6 are not consistently preserved and another 6 were the same across almost all specimens (i.e. only $<2$ specimens exhibited a different character). Thus, there are only two discrete characters that show variability within each of the three Primocandelabrum species: $1^{\text {st }}$ order branch concealment/unconcealment and $2^{\text {nd }}$ order radiating/subparallel branch arrangement (Figure 2, Table 1).

A spatial map was constructed of the B Bed community using Reflectance Transformation Images (RTI) of $\sim 1 \times 1 \mathrm{~m}$ casts of the surface (Kenchington et al. 2018). These were placed in their correct spatial positions by georeferencing them to a LiDAR scan of the entire surface.

Each specimen was then assigned its morphological characters and taxonomic identity (Table 1), and these characters were then compared using random labelling spatial analyses (cf. Mitchell and Butterfield 2018).

\section{Methods}

Previous work on Ediacaran spatial ecology has focussed on investigating the processes that led to the fossil positions, such as dispersal, habitat associations or resource competition (Mitchell et al. 2015, Mitchell and Butterfield 2018, Mitchell and Kenchington 2018). In this study, we are not investigating the origination of fossil positions, but are instead concerned with the spatial distributions of characters within those fossil locations. This requires a different approach, and relies on Random Labelling Analyses (RLAs) (Jacquemyn et al. 2010, Raventós et al. 2010). RLAs are a type of spatial point process analysis whereby random models are simulated whilst the positions of the specimens remain the same and a given character state, such as species definition or nature of rangeomorph branching (Fig. 4), is repeatedly permutated (Fig. allocated to them (representing different character states) is changed. Applied to Bed 'B', the 
fossil locations stay the same, but whether each fossil exhibits concealed $1^{\text {st }}$ order branching or not, for example, is changed randomly in each simulation. As such, RLAs do not directly measure the aggregation or segregation between two populations, so do not test the processes that resulted in fossil location, but instead measure the differences in spatial distributions of characters between two populations.

Spatial distributions are commonly described using pair correlation functions (PCFs) which describe how the density of points (i.e. fossil specimens) changes as a function of distance (e.g. Illian et al. 2011). RLAs assess the differences between two characters of the populations by calculating variations between PCFs by considering the Difference and Quotient tests (Wiegand and Moloney 2013). The Difference test is the calculation of the distribution of $\mathrm{PCF}_{11}$ - $\mathrm{PCF}_{22}$, where $\mathrm{PCF}_{11}$ is the univariate PCF for group 1 and $\mathrm{PCF}_{22}$ is the univariate PCF for group 2. If $\mathrm{PCF}_{11}-\mathrm{PCF}_{22}=0$ then both groups are randomly distributed within the locations (i.e. both groups exhibit the same spatial behaviour). If $\mathrm{PCF}_{11}-\mathrm{PCF}_{22}>0$, then group 1 is more aggregated than group 2; if $\mathrm{PCF}_{11}-\mathrm{PCF}_{22}<0$, then group 2 is more aggregated than group 1. The Quotient test calculates the bivariate PCF between groups relative to the pattern of both groups taken together (the joined pattern), where $\mathrm{PCF}_{12}$ is the bivariate distribution of group 2 relative to group 1 and $\mathrm{PCF}_{21}$ is the bivariate distribution of group 1 relative to group 2 . For joint patterns, $\mathrm{PCF}_{1,1+2}$ is the bivariate distribution of group 1 relative to both groups together, and $\mathrm{PCF}_{2,2+1}$ is the bivariate distribution of group 2 relative to the joint pattern. Thus, the Quotient test is the calculation of the distribution: $\mathrm{PCF}_{1,1+2}-\mathrm{PCF}_{21} / \mathrm{PCF}_{2,2+1}$ where $\mathrm{PCF}_{12} / \mathrm{PCF}_{1,1+2}-$ $\mathrm{PCF}_{21} / \mathrm{PCF}_{2,2+1}>0$ indicates that group 2 is mainly located in areas with high density of the joint pattern, and group 1 is in low density areas (i.e. that group 2 has more neighbours than group 1). If this quotient is significantly non-zero, then the process underlying the characters is density-dependent; for example, concealment occurs more commonly in high-density areas.

Establishing whether the null hypotheses of the Difference and Quotient Tests should be rejected or not is complicated, because there is a lack of independence of the spatial points (fossil positions) and variety of different point pattern distributions (Illian et al. 2008). Two different methods are commonly used to establish acceptance or rejection of the null hypotheses for ecological data (e.g. Wiegand and Moloney 2013 and references therein): 1) Monte Carlo simulations (Illian et al. 2008), and 2) Diggle's goodness-of-fit test $p_{d}$, which represents the total squared deviation between the observed pattern and the stimulated pattern across the studied 
distances (Diggle 2003). The two comparisons are used together because: 1) the Monte Carlo simulation envelopes do not necessarily correspond to confidence intervals, and they run the risk of Type I errors if the observed PCF falls near the edge of the simulation envelope (Illian et al. 2008); 2) The $p_{d}$ does not strictly test whether a model should be accepted or rejected, but rather whether the test calculation for the observed data is within the range of the stochastic realization of the null hypothesis (Diggle 2003); and 3) The $p_{d}$ depends on the range over which it is calculated, meaning that the model may not fit at very small distances due to the physical occupation of that space by the organisms themselves, but may fit well at larger distances (Diggle 2003; Illian et al. 2008). Thus, visual inspection of the PCFs with Monte Carlo simulation envelopes, coupled with $p_{d}$, ensures that these errors are minimized. The underlying mathematics is described in detail by Wiegand and Moloney (2004) and Wiegand et al. (2004, 2006).

Here, we test seven null hypotheses $\left(\mathrm{H}_{0}\right)$ using RLA of character/species data and the specimen positions on the Bed B surface:

1) $\quad \mathbf{H}_{0}{ }^{\mathrm{Sp}}$ : Primocandelabrum species do not exhibit significantly different spatial distributions (PCFs) to that of the dumbbell taxon.

2-4) $\mathbf{H}_{0}{ }^{\text {boyn }} ; \mathbf{H}_{\mathbf{0}}{ }^{\text {aeth }} ; \mathbf{H}_{0}{ }^{\text {aelf }}$ : The bivariate PCFs of the three Primocandelabrum species, $P$. boyntoni, $P$. aethelfalaedia and $P$. aelfwynnia, do not differ significantly from each other.

5) $\mathbf{H}_{0}{ }^{\text {concealed: }}$ The spatial distributions of concealed or unconcealed $1^{\text {st }}$ order branches are not significantly different.

6) $\mathbf{H}_{0}$ radiation: The spatial distribution of radiation versus sub-parallel $2^{\text {nd }}$ order branches are not significantly different.

The following RLAs were conducted using Programita software (Wiegand and Moloney 2004, Wiegand et al. 2004, 2006, 2009, 2010):

1) To test $\mathrm{H}_{0}$ Sp, the univariate PCFs of the Primocandelabrum species and of the dumbbell taxon $\left(\mathrm{PCF}_{11}\right.$ and $\left.\mathrm{PCF}_{22}\right)$ were calculated by creating a distribution map of each taxon according to a $1 \mathrm{~cm} \times 1 \mathrm{~cm}$ grid of the Bed B surface within which the taxon density was calculated. The Difference test was then performed between the two groups. 
2) To test $\mathrm{H}_{0}{ }^{\text {boyn }}, \mathrm{H}_{0}{ }^{\text {aeth }}$ and $\mathrm{H}_{0}{ }^{\text {aelf }}$, the Difference test was performed between the named species group and the other two species grouped together. Two species were grouped together to enable a sufficient sample size to run the analyses. If a pair of species has significantly the same spatial distributions, as would be expected if they were one species and not two, then we should expect that there is not be a significant difference between spatial distributions that incorporate either of the species. For example, if species $\mathrm{A}$ and $\mathrm{B}$ are the same and $\mathrm{C}$ is a different species, the spatial distributions of $\mathrm{A}+\mathrm{B}$ will differ to $\mathrm{C}$. Furthermore, if either $\mathrm{A}$ or $\mathrm{B}$ is incorporated into a grouping with $\mathrm{C}$ and then compared against the remaining species (e.g. $\mathrm{A}+\mathrm{C}$ compared to B), the result will not be significantly different because the pattern of A will mask any differences to $\mathrm{C}$.

3) To test $\mathrm{H}_{0}{ }^{\text {concealed, }}$, the Difference test was used to assess whether there was a significant difference between the PCFs of each species, and the Quotient test was used to assess whether any of the differences found depended on specimen density.

4) To test $\mathrm{H}_{0}{ }^{\text {radiation }}$, the Difference and Quotient tests were used to assess whether the spatial distribution of $2^{\text {nd }}$ order radiating/displayed varied regardless of taxonomic affinity.

Each hypothesis was tested by running 999 Monte Carlo simulations for each group in order to generate simulation envelopes around the random (i.e. $\mathrm{PCF}_{11}-\mathrm{PCF}_{22}=0$ ). $p_{d}$ values were calculated using Diggle's goodness-of-fit test (Diggle 2003). 999 simulations were run (instead of 1000 , for example) because the $p_{d}$ value is calculated using the model simulation data (not the theoretical model), so by using 999 the $p_{d}$ simulations could be measured in 0.001 increments. If the observed $\mathrm{PCF}_{11}-\mathrm{PCF}_{22}$ fell outside the RLA simulation envelopes and had $p_{d}<0.1$, then the distributions were found to be significantly different.

Random labelling analyses hold the positions of the specimens constant so that if taphonomic processes (cf. Kenchington and Wilby 2014) impact all groups similarly, as might reasonably be expected for mutually aligned and simultaneously buried specimens (see Wilby et al 2011, 2015), then they are independent of the RLAs. This property of RLAs means that a subsample of the total population can be analysed. Our data is a subsample of the total population of multifoliate rangeomorphs on Bed 'B' (only well preserved specimens were used), 
so only differences between spatial distributions of specimen positions and density dependence can be tested. Examination of species dispersal and/or inter-specific interactions (cf. Mitchell et al. 2015, Mitchell and Butterfield 2018) require the whole population, so are not considered here.

\section{Results}

259 We reject null hypothesis $\mathrm{H}_{0} \mathrm{Sp}$ because the low $p_{d}$ value and excursions outside of the simulation envelope from the difference test shows that Primocandelabrum versus non-Primocandelabrum had significantly different spatial patterns $\left(p_{d}=0.057\right.$; Fig. 5a). $\mathrm{H}_{0}{ }^{\text {aeth }}$ is also rejected because P. aethelfalaedia had a significantly different spatial pattern to $P$. boyntoni and P. aelfwynnia $\left(p_{d}\right.$ $=0.083$; Fig. 5 b). $\mathrm{H}_{0}{ }^{\text {boyn }}$ and $\mathrm{H}_{0}$ aelf are accepted because no significant difference was found for either P. boyntoni or P. aelfwynnia $\left(p_{d}>>0.1\right) . \mathrm{H}_{0}{ }^{\text {radiation }}$ is also accepted: there is no difference in spatial distributions between the presence of $2^{\text {nd }}$ order radiating or subparallel branching $\left(p_{d}>>0.1\right) . \mathrm{H}_{0}{ }^{\text {concealed }}$ is rejected because Concealed versus Unconcealed $1^{\text {st }}$ order branches exhibit significantly different spatial distributions $\left(p_{d}=0.024 ;\right.$ Fig. $\left.5 \mathrm{c}\right)$ and density dependant behaviour $\left(p_{d}=0.035\right.$; Fig. $\left.5 \mathrm{~d}\right)$. Unconcealed branching occurrs in the higher density areas, and concealed $1^{\text {st }}$ order branching occurs in the lower density areas. The $p_{d}$ value for $\mathrm{H}_{0}$ concealed is smaller than those found between different species, suggesting that the spatial signal of concealment is stronger than that of the constituent species and, consequently, that the differences are not taxonomically controlled.

\section{Discussion}

275 Currently, there is no consensus regarding the taxonomic value of particular rangeomorph characters and there are competing taxonomic schemes in operation (Braiser et al. 2012, Laflamme et al. 2012, Liu et al. 2016). This study presents a methodology for assessing the utility of discreet characters in rangeomorph taxonomy which is independent of specimen morphology, with important implications for rangeomorph taxonomic identification, Ediacaran species richness analyses, and identification of phylogenetically useful rangeomorph characters.

283 For sessile organisms, there are four different types of processes that impact their spatial distribution: physical environment (Wiegand et al. 2007a), organism dispersal/reproduction 
(Seidler and Plotkin 2006), interspecific interactions such as competition for resources (Getzin et

286

al. 2006) and/pr facilitation (Lingua et al. 2008), and differential mortality processes, such as Janzell-Cornell effects (Getzin et al. 2008). The combination of these different processes rarely impacts two species populations in exactly the same way: for example, while two species may respond similarly to a local environmental heterogeneity, their dispersal processes are most likely different. As such, while it's never possible to be $100 \%$ certain about the underlying processes behind spatial distributions (Lin et al. 2011,Wiegand and Molony 2004, Wiegand et al. 2007), one can be confident that if two species have the same spatial distributions they are most likely to be formed by the same underlying processes and, thus most likely be a single species. This approach is verified for Ediacaran populations by the fact that the dumbbell taxon and the Primocandelabrum species exhibit significantly different spatial distributions (Fig 5a).

Prior analyses suggested that there are either two or three species of Primocandelabrum on Bed 'B' (Fig. 3, Kenchington and Wilby 2017) and that the morphological distinctiveness of $P$. aethelflaedia is greater than the morphological differences between $P$. boyntoni and $P$. aelfwynnia (Fig 5b). Our analyses confirm this result by an independent means, finding that $P$. aethelflaedia exhibits significantly different spatial distribution compared to P. boyntoni and $P$. aelfwynnia. The similarities in the spatial behaviour of P. boyntoni and P. aelfwynnia suggests that they were most likely subject to the same processes, which is most consistent with them being one taxon, not two. As such, their synonymization should be considered.

\section{Species richness estimates}

Ediacaran organisms provide the earliest evidence of complex life and underpin our understanding of early radiations and possible extinction within the animal kingdom over the Ediacaran to Cambrian transition (e.g. Shen et al. 2008, Darroch et al. 2013). Key to this is a reliable means of determining species richness. With only relatively few Ediacaran taxa described globally ( 124 taxa, Boag et al. 2016), Ediacaran macro-evolutionary patterns are particularly sensitive to small changes in species richness. The accuracy of such diversity studies depends on accurate taxonomic frameworks, which are currently in a state of flux (e.g. Laflamme at al. 2012, Liu et al. 2016). This study demonstrated that there are most likely two, not three, Primocandelabrum species present on Bed 'B'. If this situation is at all representative, it is possible that Avalonian taxonomic diversity has been inflated $(\sim 25$ species are currently 
described, Liu et al. 2015) and, thus, that the species richness of these early complex communities has been overestimated.

\section{Ecophenotypism}

The identification of phylogenetic, ontological and/or ecophenotypic characters is especially difficult for rangeomorphs because they are endemic to the Ediacaran time period, with only a couple of putative Ediacaran survivors (e.g. Muscante et al. 2017). We find that the concealment of $1^{\text {st }}$ order branches is strongly density dependent, with concealment occurring in the low density areas of the community and unconcealment in the high density areas. Concealment of a branch is defined when the central axis covered by its secondary branches so is not visible (Brasier et al. 2012), and may be related to the efficiency of branch packing. In high density areas, competition for resources (such as water-column nutrients or neighbour shading) is likely to be more intense (e.g. Tanner et al. 2009), and organisms may adapt in ways which aren't beneficial in lower densities areas. Theoretically, packing efficiency could be compromised in order to increase the exposure of branches to the water column, and therefore enhance nutrient uptake. We postulate that concealed $1^{\text {st }}$ order branches may have allowed sufficient nutrient uptake in low-competition areas but, in areas of higher competition, having unconcealed $1^{\text {st }}$ order rangeomorph branches outweighed the advantages of more efficient branch packing.

Alternatively, it is possible that $1^{\text {st }}$ order concealment does not record an in-life response to differing community densities, but rather a taphonomic artefact induced by different fluid flow conditions within communities of different density (cf. Ghisalberti et al. 2014). Currently, the underlying process(es) behind the response remain uncertain.

\section{There is no direct correlation between concealment and taxonomic assignment within}

Primocanelabrum: all three Primocandelabrum species exhibit both concealed and unconcealed first order branches. However, different taxa may have had different abilities to conceal their branches, so while our analyses show that concealment could be an environmental response, it may also have a weak taxonomic signal. Whatever the cause, because the density signal of concealment imparts a much stronger signal than any taxonomic one, this character should be used with caution when defining taxa and investigating rangeomorph phylogenies (cf. Decchecci 
et al. 2017). In contrast, the radiation of the $2^{\text {nd }}$ order branches does appear to be a biological signal.

\section{Utility of spatial analyses for taxonomic investigations}

This study provided a way to assess taxonomic identity that is independent of multivariate morphological analyses commonly employed for rangeomorphs (e.g. Gehling et al. 2007, Laflamme et al. 2004, 2008). Our results strongly support previous morphological analyses of the same Primocandelabrum populations on Bed 'B' (Kenchington and Wilby 2017). These analyses enable investigation of environmental impact on characters beyond previous morphological analyses. While previous analyses demonstrated that concealment of $1^{\text {st }}$ order branches was a useful discreet character by which to help discriminate Primocandelabrum species from each other and from Dumbbell (as Dumbbell is very rarely unconcealed), we instead found that the variation of concealment within all taxa (both Dumbbell and Primocandelabrum) was strongly dependent on specimen density, much more so than with taxonomic affinity. Thus, the RLAs have found a hitherto unknown signal that was not possible to identify from morphological analyses alone. It highlights the potential for other characters, both discreet and continuous, to be taxonomically irrelevant.

\section{Conclusions}

Detailed analyses of Primocandelabrum species suggests that there are most likely two, not three, different species of Primocandelabrum present on the bed 'B' surface of Charnwood Forest. This result is consistent with previous work using morphological statistical analyses, which found P. aethelfalaedia to be the most different of the Primocandelabrum species (Fig. 2; Kenchington and Wilby 2017), thus presenting an independent method of confirming morphological analyses. We have shown that there is significant density dependence to whether $1^{\text {st }}$ order branches are concealed or unconcealed. Specimens with unconcealed primary branches were found to occupy the higher-density areas of the Primocandelabrum community, while specimens with concealed primary branches occupied the lower density areas. This signal is distinct from the taxonomic results, which identified the concealed/unconcealed character as being taxonomically useful. Our findings suggest that all of the studied multi-foilate 
rangeomorphs had the potential to exhibit unconcealed $1^{\text {st }}$ order branches in high density areas, demonstrating the capacity of rangeomorphs to respond to their local environment.

\section{Acknowledgements}

EGM has been supported by the Natural Environment Research Council [grant number NE/P002412/1], Gibbs Travelling Fellowship from Newnham College, Cambridge and a Henslow Research Fellowship from Cambridge Philosophical Society. Phil Vixseboxse is thanked for his help in producing the RTIs. CGK and PRW were funded by National Environment Research Council grant NE/1005927/1. CGK also acknowledges a Research Studentship funded by the Cambridge Philosophical Society. Access to Bed B was kindly facilitated by Natural England and landowners in Charnwood Forest.

\section{References}

Boag, T.H., Darroch, S.A. and Laflamme, M., 2016. Ediacaran distributions in space and time: testing assemblage concepts of earliest macroscopic body fossils. Paleobiology, 42(4):574-594. Brasier, M. D., J. B. Antcliffe, and A. G. Liu. 2012. The architecture of Ediacaran fronds. Palaeontology 55:1105-1124.

Clapham, M. E., G. M. Narbonne, and J. G. Gehling. 2003. Paleoecology of the oldest known animal communities: Ediacaran assemblages at Mistaken Point, Newfoundland. Paleobiology 29:527-544.

Darroch, S.A., Laflamme, M. and Clapham, M.E., 2013. Population structure of the oldest known macroscopic communities from Mistaken Point, Newfoundland. Paleobiology, 39(4), 591-608.

Darroch, S.A., Sperling, E.A., Boag, T.H., Racicot, R.A., Mason, S.J., Morgan, A.S., Tweedt, S., Myrow, P., Johnston, D.T., Erwin, D.H. and Laflamme, M., 2015. Biotic replacement and mass extinction of the Ediacara biota. Proc. R. Soc. B 282:20151003.

Dececchi, T. A., G. M. Narbonne, C. Greentree, and M. Laflamme. 2017. Relating Ediacaran fronds. Paleobiology 43:171-180.

Diggle, P. 2003. Statistical analysis of spatial point patterns, 2nd ed. Arnold, London. 
The Cambrian conundrum: early divergence and later ecological success in the early history of animals. science, 334(6059),1091-1097. Point assemblage, Avalon Zone, Newfoundland. Canadian Journal of Earth Sciences, 44(3): 367387.

Getzin, S., Ch. Dean, F. He, J. A Trofymow, K. Wiegand, and T. Wiegand. 2006. Spatial patterns and competition of tree species in a Douglas-fir chronosequence on Vancouver Island. Ecography 29:671-682.

Getzin, S., T. W., K. Wiegand, and F. He. 2008. Heterogeneity influences spatial patterns and demographics in forest stands. Journal of Ecology 96:807-820.

Hofmann, H.J., O'brien, S.J. and King, A.F., 2008. Ediacaran biota on Bonavista peninsula, Newfoundland, Canada. Journal of Paleontology, 82(1): 1-36.

Hoyal Cuthill, J. F., and S. Conway Morris. 2014. Fractal branching organizations of Ediacaran rangeomorph fronds reveal a lost Proterozoic body plan. Proceedings of the National Academy of Sciences USA 111:13122-13126. Illian, J., A. Penttinen, H. Stoyan, and D. Stoyan. 2008. Statistical analysis and modelling of spatial point patterns. Statistics in practice, Vol. 70. Wiley, Chichester, U.K. interventions in small populations of a perennial herb Primula vulgaris using spatio-temporal analyses of point patterns. Journal of Applied Ecology 47:431-440. fossils of Charnwood Forest: Shining new light on a major biological revolution. Proceedings of the Geologists' Association. 10.1016/j.pgeola.2018.02.006.

Kenchington, C. G., and P. R Wilby. 2014. Of time and taphonomy: preservation in the Ediacaran. Edited by M. Laflamme, J. D. Schiffbauer, and S. A. F. Darroch, eds. Reading and writing of the fossil record: preservational pathways to exceptional fossilization. Paleontological Society Papers 20:101-122.

Kenchington, C.G. and Wilby, P.R., 2017. Rangeomorph classification schemes and intraspecific variation: are all characters created equal?. Geological Society, London, Special Publications, 448(1): 221-250. 
Laflamme, M. and Narbonne, G.M., 2008. Ediacaran fronds. Palaeogeography,

Palaeoclimatology, Palaeoecology, 258(3): 162-179.

Laflamme, M. Narbonne, G.M. and Anderson, M.M., 2004. Morphometric analysis of the Ediacaran frond Charniodiscus from the Mistaken Point Formation, Newfoundland. Journal of Paleontology, 78(5): 827-837.

Laflamme, M., Flude, L.I. and Narbonne, G.M., 2012. Ecological tiering and the evolution of a stem: the oldest stemmed frond from the Ediacaran of Newfoundland, Canada. Journal of Paleontology, 86(2), 193-200.

Lin, Y. C., L. W. Chang, K. C. Yang, H. H. Wang, and I. F. Sun. 2011. Point patterns of tree distribution determined by habitat heterogeneity and dispersal limitation. Oecologia, 165:175184.

Lingua, E., Cherubini, P., Motta, R. and Nola, P., 2008. Spatial structure along an altitudinal gradient in the Italian central Alps suggests competition and facilitation among coniferous species. Journal of Vegetation Science, 19(3): 425-436.

Liu, A. G., C. G. Kenchington, and E. G. Mitchell. 2015. Remarkable insights into the paleoecology of the Avalonian Ediacaran macrobiota. Gondwana Research 27:1355-1380.

Liu, A.G., 2016. Framboidal pyrite shroud confirms the 'death mask'model for moldic preservation of Ediacaran soft-bodied organisms. Palaios, 31(5): 259-274.

Liu, A.G., Matthews, J.J. and McIlroy, D., 2016. The Beothukis/Culmofrons problem and its bearing on Ediacaran macrofossil taxonomy: evidence from an exceptional new fossil locality. Palaeontology, 59(1): 45-58.

Mitchell, E. G. and C. G. Kenchington. 2018. The utility of height for Ediacaran organisms of Mistaken Point, Nature Ecology and Evolution, in press.

Mitchell, E. G., C. G. Kenchington, A. G. Liu, J. J. Matthews, and N. J. Butterfield. 2015.

Reconstructing the reproductive mode of an Ediacaran macro-organism. Nature 524:343.

Mitchell, E. G.,and N. J. Butterfield. 2018. Spatial analyses of Ediacaran organisms of Mistaken Point, Paleobiology, 44(1): 40-57.

Muscente, A.D., Boag, T.H., Bykova, N. and Schiffbauer, J.D., 2017. Environmental disturbance, resource availability, and biologic turnover at the dawn of animal life. Earth-Science

Reviews. 177: 248-264. 
Narbonne, G. M. 2004. Modular construction of early Ediacaran complex life forms.

Science 305: 1141-1144.

Narbonne, G.M., Laflamme, M., Greentree, C. and Trusler, P., 2009. Reconstructing a lost world: Ediacaran rangeomorphs from Spaniard's Bay, Newfoundland. Journal of Paleontology, 83(4): 503-523.

Noble, S.R., Condon, D.J., Carney, J.N., Wilby, P.R., Pharaoh, T.C. and Ford, T.D., 2015. U-Pb geochronology and global context of the Charnian Supergroup, UK: constraints on the age of key Ediacaran fossil assemblages. Geological Society of America Bulletin, 127(1-2): 250-265.

Raventós, J., T. Wiegand, and M. De Luis. 2010. Evidence for the spatial segregation hypothesis: a test with nine year survivorship data in a Mediterranean shrubland. Ecology 91:2110-2120.

Seidler, T. G., and J. B. Plotkin. 2006. Seed dispersal and spatial pattern in tropical trees. PLoS Biology 4:e344.

Shen, B., Dong, L., Xiao, S. and Kowalewski, M., 2008. The Avalon explosion: evolution of Ediacara morphospace. Science, 319(5859): 81-84.

Tanner, J.E., Hughes, T.P. and Connell, J.H., 2009. Community-level density dependence: an example from a shallow coral assemblage. Ecology, 90(2): 506-516.

Velázquez, E., M. Kazmierczak, and T. Wiegand. 2016. Spatial patterns of sapling mortality in a moist tropical forest: consistency with total density dependent effects. Oikos 125:872-882. Wiegand, T., A. Huth, S. Getzin, X. Wang, Z. Hao, C. V. S. Gunatilleke, and I. N. Gunatilleke. 2012. Testing the independent species' arrangement assertion made by theories of stochastic geometry of biodiversity. Proceedings of the Royal Society of London B 279: 10.1098/rspb.2012.0376.

Wiegand, T., and K. A. Moloney. 2004. Rings, circles, and null-models for point pattern analysis in ecology. Oikos 104:209-229.

Wiegand, T., and K. A. Moloney. 2013. Handbook of spatial point-pattern analysis in ecology. CRC, Boca Raton, Fla.

Wiegand, T., I. Martínez, and A. Huth. 2009. Recruitment in tropical tree species: revealing complex spatial patterns. American Naturalist 174:E106-E140.

Wiegand, T., S. Gunatilleke, and N. Gunatilleke. 2007a. Species associations in a heterogeneous Sri Lankan dipterocarp forest. American Naturalist 170:E77-E95. 
Wiegand, T., S. Gunatilleke, N. Gunatilleke, and T. Okuda. 2007b. Analyzing the spatial structure of a Sri Lankan tree species with multiple scales of clustering. Ecology 88:3088-3102.

498 Wiegand, T., W. D. Kissling, P. A. Cipriotti, and M. R. Aguiar. 2006. Extending point pattern 499 analysis for objects of finite size and irregular shape. Journal of Ecology 94:825-837.

500 Wilby, P. R., J. N. Carney, and M. P.A. Howe. 2011. A rich Ediacaran assemblage from eastern 501 Avalonia: evidence of early widespread diversity in the deep ocean. Geology 39:655-658.

502 Wilby, P.R., Kenchington, C.G. and Wilby, R.L., 2015. Role of low intensity environmental 503 disturbance in structuring the earliest (Ediacaran) macrobenthic tiered communities.

504 Palaeogeography, Palaeoclimatology, Palaeoecology, 434,14-27.

505 Wood, D. A., R. W. Dalrymple, G. M. Narbonne, J. G. Gehling, and M. E. Clapham. 2003.

506 Paleoenvironmental analysis of the late Neoproterozoic Mistaken Point and Trepassey

507 formations, south-eastern Newfoundland. Canadian Journal of Earth Sciences 40:1375-1391.

508 Xiao, S. and Laflamme, M., 2009. On the eve of animal radiation: phylogeny, ecology and

509 evolution of the Ediacara biota. Trends in Ecology \& Evolution, 24(1), 31-40.

510 Yamamichi, M., Yoshida, T. and Sasaki, A., 2014. Timing and propagule size of invasion

511 determine its success by a time-varying threshold of demographic regime shift. Ecology, 95(8):

$512 \quad 2303-2315$.

513 


\begin{tabular}{|c|c|c|c|}
\hline Specimen ID & Species ID & $\begin{array}{c}1 \text { st } \\
\text { Concealed? }\end{array}$ & $\begin{array}{c}\text { 2nd } \\
\text { Radiating? }\end{array}$ \\
\hline $10 \mathrm{C} 3 \mathrm{c}$ & P. aelfwynnia & unconcealed & subparallel \\
\hline $3(1)$ & P. aelfwynnia & unconcealed & \\
\hline $3(2)$ & P. aelfwynnia & unconcealed & radiating \\
\hline 3D8 & P. aelfwynnia & concealed & subparallel \\
\hline $8 \mathrm{~B} 3 \mathrm{~b}$ & P. aelfwynnia & concealed & radiating \\
\hline $8 \mathrm{C} 2$ & P. aelfwynnia & unconcealed & radiating \\
\hline Big Bertha & P. aelfwynnia & & subparallel \\
\hline $5 \mathrm{E} 2$ & P. aethelflaedia & concealed & subparallel \\
\hline 10B10 & P. aethelflaedia & concealed & radiating \\
\hline $10 \mathrm{C} 4$ & P. aethelflaedia & & \\
\hline $3 \mathrm{C} 3$ & P. aethelflaedia & concealed & radiating \\
\hline 4A1b (right) & P. aethelflaedia & concealed & subparallel \\
\hline $5 \mathrm{C} 1$ & P. aethelflaedia & & \\
\hline $5 \mathrm{~F} 3$ & P. aethelflaedia & concealed & subparallel \\
\hline $5 \mathrm{~F} 5$ & P. aethelflaedia & concealed & \\
\hline $5 \mathrm{E} 3$ & P. boyntoni & concealed & radiating \\
\hline 10B3 & P. boyntoni & concealed & radiating \\
\hline 10B8 & P. boyntoni & concealed & \\
\hline $10 \mathrm{C} 3 \mathrm{~b}$ & P. boyntoni & unconcealed & subparallel \\
\hline $10 \mathrm{C} 8$ & P. boyntoni & concealed & subparallel \\
\hline $13 \mathrm{~A} 8$ & P. boyntoni & & radiating \\
\hline 1B1 & P. boyntoni & unconcealed & radiating \\
\hline 2B1 & P. boyntoni & unconcealed & \\
\hline $4 \mathrm{~A} 3$ & P. boyntoni & unconcealed & subparallel \\
\hline 4B3 & P. boyntoni & concealed & radiating \\
\hline $5 \mathrm{C} 5$ & P. boyntoni & & \\
\hline $5 \mathrm{G} 3$ & P. boyntoni & & \\
\hline $6 a 21$ & P. boyntoni & unconcealed & radiating \\
\hline 7A4 & P. boyntoni & concealed & \\
\hline $7 \mathrm{~A} 5$ & P. boyntoni & unconcealed & subparallel \\
\hline $8 B 4$ & P. boyntoni & unconcealed & subparallel \\
\hline $5 \mathrm{~A} 4$ & Dumbbell & concealed & \\
\hline $3 \mathrm{D} 7$ & Dumbbell & concealed & \\
\hline $5 \mathrm{C} 6$ & Dumbbell & concealed & radiating \\
\hline $3 \mathrm{E} 1(1)$ & Dumbbell & concealed & radiating \\
\hline $8 \mathrm{C} 1$ & Dumbbell & unconcealed & subparallel \\
\hline $10 \mathrm{C} 3 \mathrm{c}$ & P. aelfwynnia & unconcealed & subparallel \\
\hline $3(1)$ & P. aelfwynnia & unconcealed & \\
\hline $3(2)$ & P. aelfwynnia & unconcealed & radiating \\
\hline $3 \mathrm{D} 8$ & P. aelfwynnia & concealed & subparallel \\
\hline $8 \mathrm{~B} 3 \mathrm{~b}$ & P. aelfwynnia & concealed & radiating \\
\hline $8 \mathrm{C} 2$ & P. aelfwynnia & unconcealed & radiating \\
\hline Big Bertha & P. aelfwynnia & & subparallel \\
\hline $5 \mathrm{E} 2$ & P. aethelflaedia & concealed & subparallel \\
\hline 10B10 & P. aethelflaedia & concealed & radiating \\
\hline $10 \mathrm{C} 4$ & P. aethelflaedia & & \\
\hline $3 \mathrm{C} 3$ & P. aethelflaedia & concealed & radiating \\
\hline 4A1b (right) & P. aethelflaedia & concealed & subparallel \\
\hline $5 \mathrm{C} 1$ & P. aethelflaedia & & \\
\hline $5 \mathrm{~F} 3$ & P. aethelflaedia & concealed & subparallel \\
\hline
\end{tabular}

515 Table 1: Summary of data used in this study, taken from Kenchington and Wilby (2017). Spatial

data is available on request. 
517 Figure 1. The plastotype (specimen 6A21, GSM105969) of Primocandelabrum boyntoni from

518 Charnwood Forest, held at the British Geological Survey, Keyworth. Scale bar 2cm.

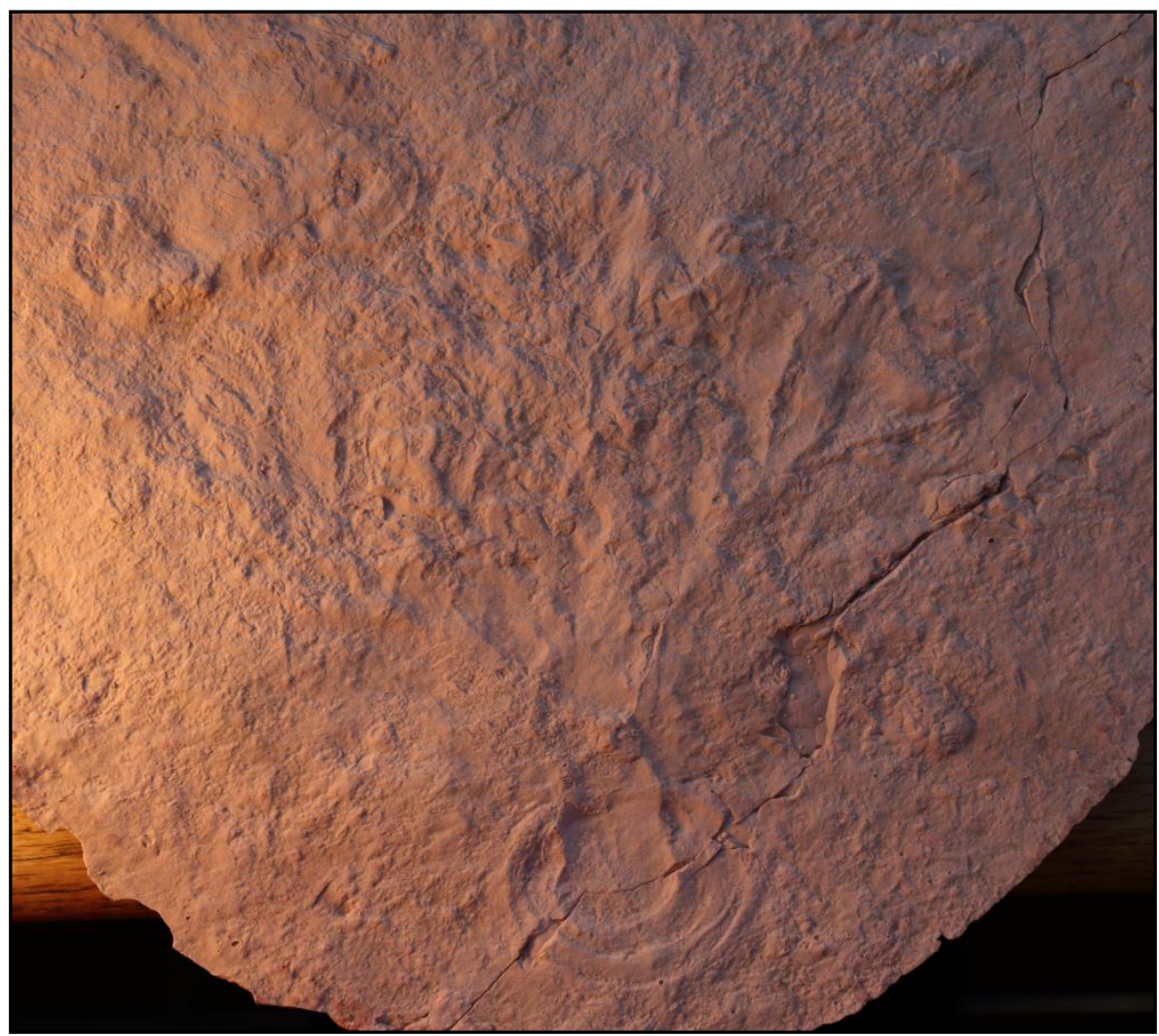

519 
Figure 2. $1^{\text {st }}$ order branch showing categorical characters. When the $1^{\text {st }}$ order branch is unconcealed, the stalk is visible (left hand side), while it is hidden if concealed (right hand side). edges are tucked to give a smooth outer margin when the $2^{\text {nd }}$ order branch is rotated (or furled).

1st order unconcealed

2nd order displayed

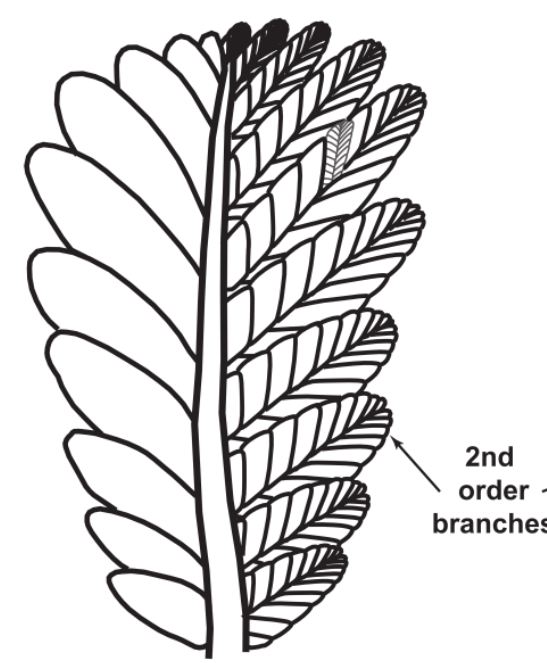

1st order concealed

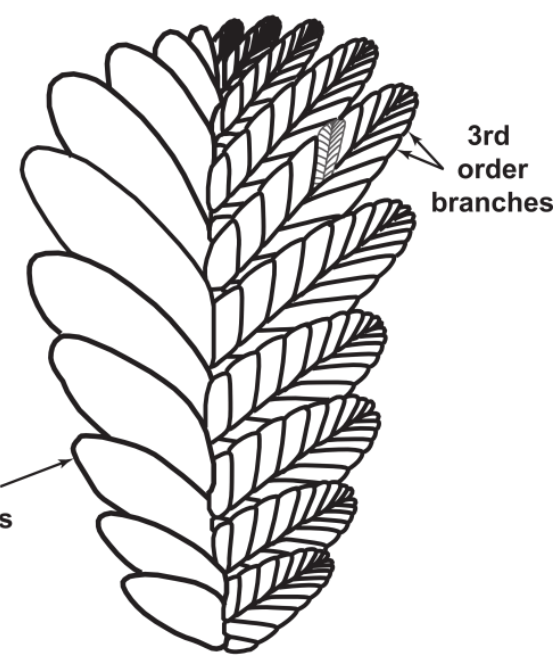

2nd order undisplayed
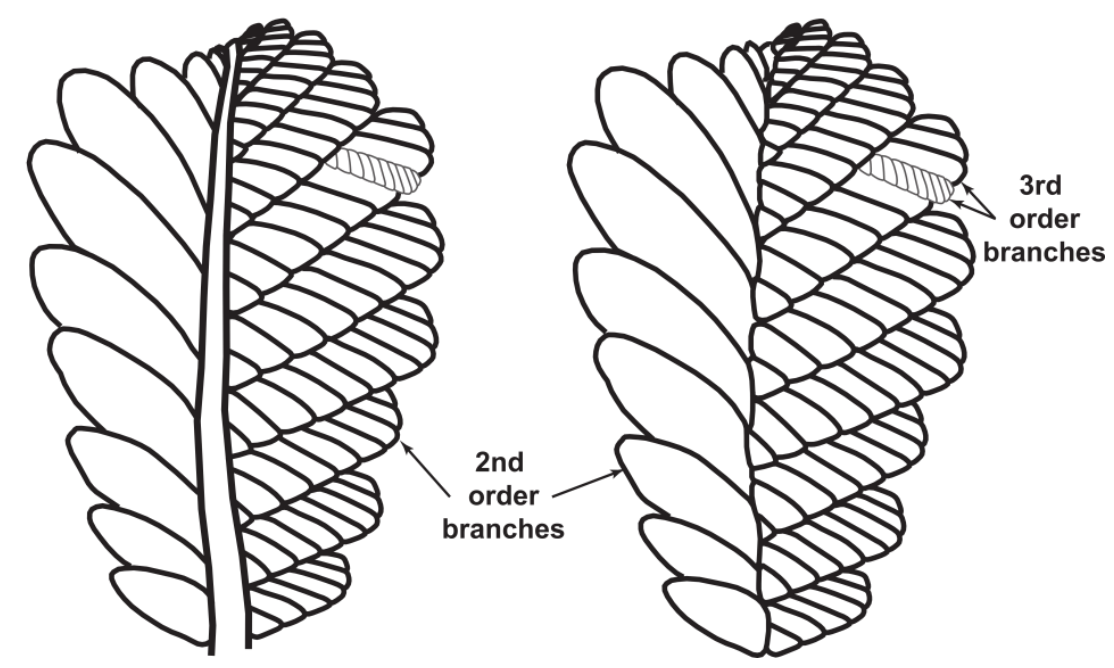
526 Figure 3. Results of the Kenchington and Wilby 2017 cluster analysis using categorical and continuous characters for the Primocandelabrum species. (a) Cluster dendrogram and (b) factor map for analysis on continuous and categorical characters. Inertia gain plots support division into

529 two or three clusters in (a). Schematic diagrams describe the clusters that match their colour.
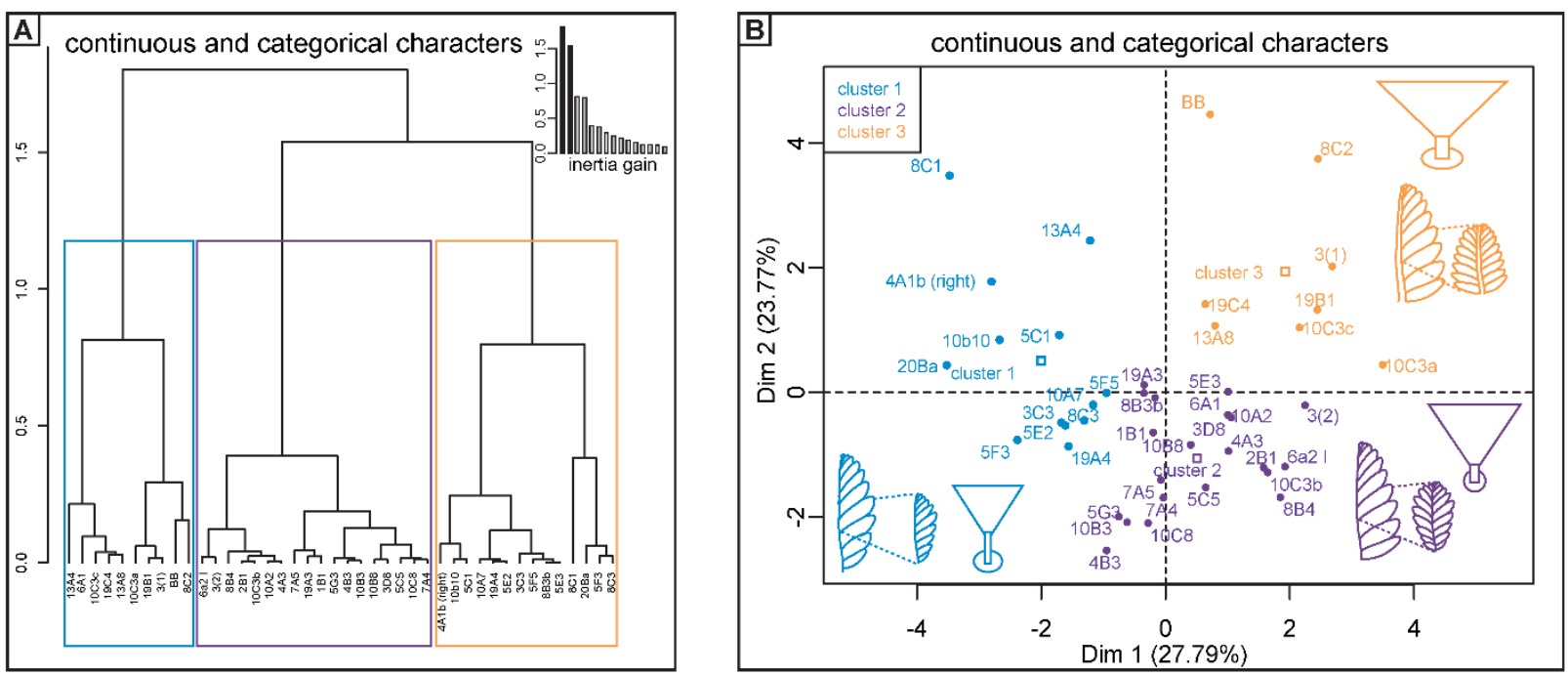
532 Figure 4: Random Labelling Analyses concept. Two character states are denoted by the white 533 and black circles. The positions of the circles remain constant, but the character state associated

534 with each circle is randomly changed using Monte Carlo simulations (a-c). The PCFs for each 535 simulation are calculated and used to generate the upper and lower boundaries expected if the 536 character states were randomly distributed over the positions.

537
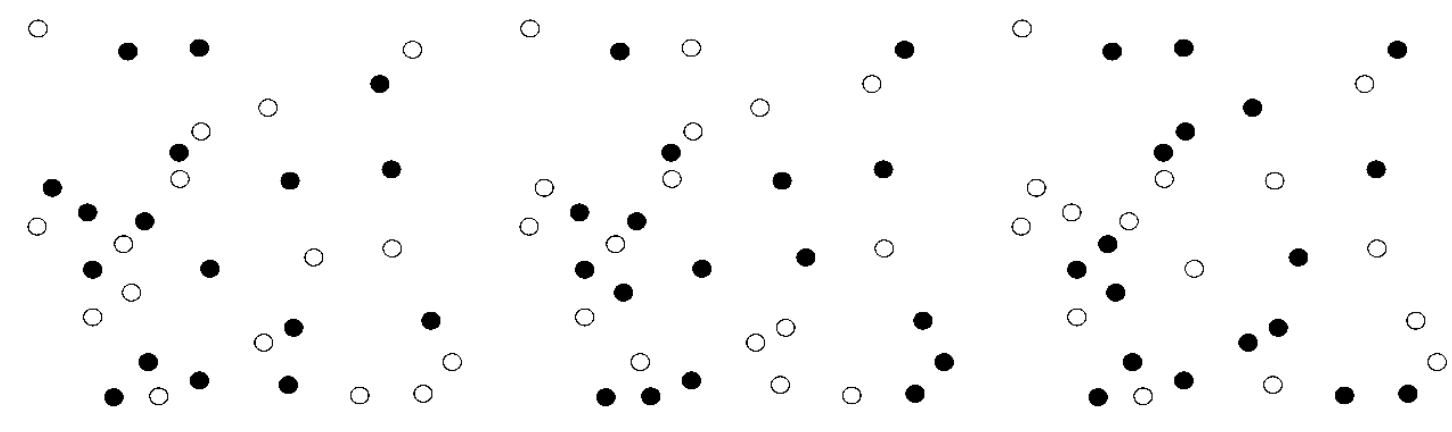
541 Figure 5. The RLA plots of all significantly non-random analyses. The distance in meters is

542 given by the $\mathrm{x}$-axis and the result of either the PCF difference or quotient is given by the y-axis.

$543 \mathrm{y}=0$ corresponds to a random distribution between groups (either species or characters).

544 Observed data is given by the black line. The grey area represents 999 RLA Monte Carlo

545 simulations. A) $\mathrm{H}_{0}{ }^{\mathrm{Sp}}$ RLA Difference test showing a significantly different spatial distribution

546 between Primocandelabrum species and the dumbbell taxon. B) $\mathrm{H}_{0}{ }^{\text {aeth }}$ Difference test showing

$547 P$. aethelfalaedia has a significantly different spatial pattern to P. boyntoni and P. aelfwynnia.

548 C) $\mathrm{H}_{0}{ }^{\text {concealed }}$ quotient test showing density dependent behaviour of the $1^{\text {st }}$ order concealment.
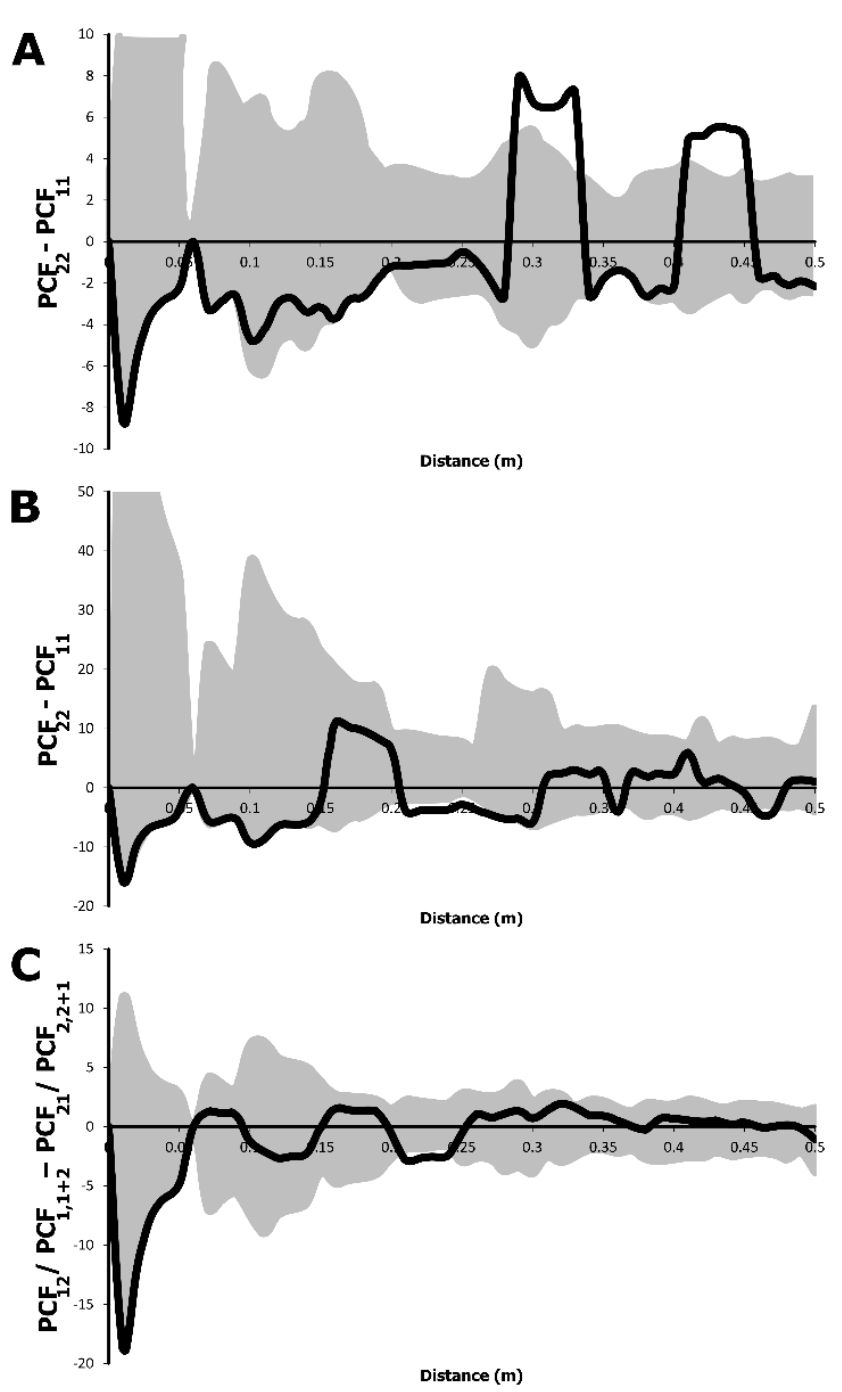